\title{
Telefones desfiados ${ }^{1}$
}

\section{RESUMO}

Independente das horas, dos dias e dos expedientes, os habitués da cidade vão deixando marcas que podem ser vistas ou ignoradas. Marcas que (e se) comunicam com cada elemento que compõem esse cenário. Os letreiros dos estabelecimentos comerciais, o mau-cheiro dos indesejáveis, as pichações nos muros, os sacos de lixos dos prédios e os cartazes nos postes e orelhões. Saí em busca de algumas dessas marcas para elaborar esse artigo/ensaio. Através dessas marcas pretendo iniciar questões referentes à ocupação, circulação e sociabilidade das travestis no espaço urbano. Nesse trabalho partirei da análise de anúncios colados em telefones públicos nas regiões da Glória/Lapa e de Copacabana. Duas áreas cariocas que abrigam pontos de circulação e prostituição de travestis. Tratarei tais anúncios como marcas deixadas pelos travestis que vivem/trabalham/circulam nesses bairros.

\section{PALAVRAS-CHAVE}

Comunicação

Cidades

Travestis

\section{ABSTRACT}

Regardless of the hours, days and expedients, the habitués of the city are leaving marks that can be viewed or ignored. Brands that (and if) communicate with each element of the scenery. Signs of shops, the smell of unwanted, graffiti on walls, trash bags from buildings and banners on poles and public telephones. I left in search of some of these brands to prepare this article/essay. Through these brands I want to start questions regarding occupation, movement and sociability of transvestites in urban space. In this work the analysis of advertisements pasted on public telephones in the regions of Glória/Lapa and Copacabana. Two areas that are points of circulation and prostitution of transvestite in Rio. I will deal with such ads as marks left by transvestites who live/work/circulate these neighborhoods.

\section{KEYWORDS}

Communication

Cities

Transvestite

\section{João Maia}

Professor do Programa de Pós-Graduaç̃o em Comunicação da UERJ/RJ/BR.

cac_mangueira@hotmail.com

\section{Leonardo Viso}

Mestrando do Programa de Pós-Graduação em Comunicação da UERJ/RJ/BR.

cac_mangueira@hotmail.com 


\section{"Próxima estação Glória. Desembarque} pelo lado direito". Às 14h36, o suor no rosto das pessoas é o melhor termômetro que a cidade pode ter. Rio-quarenta-graus deixou de ser verso de música ${ }^{2}$ para se tornar lugar-comum. Não fico ileso. Degrau por degrau, vou sentindo e vendo o Sol que domina aquela tarde de verão no Rio de Janeiro. Largo da Glória. Uma mistura de ruas, avenidas, praças e canteiros. Rua do Catete vira Rua da Glória que vira Rua da Lapa que se transforma em Largo da Lapa que vira Passeio Público que se bifurcar em Avenida Augusto Severo que se mistura com a Praça Paris que se dissolve pelo Parque do Flamengo.

Independente das horas, dos dias e dos expedientes, os habitués da mancha vão deixando marcas que podem ser vistas ou ignoradas. Marcas que (e se) comunicam com cada elemento que compõem esse cenário. Os letreiros dos estabelecimentos comerciais, o mau-cheiro dos indesejáveis, as pichações nos muros, os sacos de lixos dos prédios e os cartazes nos postes e orelhões. Saí em busca de algumas dessas marcas para elaborar esse artigo/ensaio.

Através dessas marcas pretendo iniciar questões referentes à ocupação, circulação e sociabilidade das travestis no espaço urbano. Nesse trabalho partirei da análise de anúncios colados em telefones públicos nas regiões da Glória/Lapa e de Copacabana. Duas áreas cariocas que abrigam pontos de circulação e prostituição de travestis. Tratarei tais anúncios como marcas deixadas pelos travestis que vivem/trabalham/circulam nesses bairros.

$\mathrm{Na}$ construção do ensaio dialogarei com outros autores como Michel de Certeau (estratégias e táticas), Hélio Silva (travestis), Beatriz Sarlo (vizinhança e travestis), Torres (circuito e mancha), Massimo Canevacci (zonas e interstícios) e Judith Butler (gênero e perfomance).

\section{Manchas desmarcadas}

Quando cheguei a Rua da Glória tentei me lembrar das vezes em que caminhei por lá. Foram poucas oportunidades. Quase sempre com pressa e quase nunca à noite. Porém, por meses passei de madrugada por ali de carro ou de ônibus. A cena de todas as noites era quase a mesma: usuários de drogas e moradores de ruas zanzando que nem zumbis e travestis corpulentas trabalhando sob a luz dos postes. Não teve uma madrugada em que esses personagens não estivessem ali. Dias quentes, chuvosos ou frios. Lá estavam eles. Menos numerosos, em certas ocasiões, mas sempre presentes.

$\mathrm{Na}$ tarde do dia 23 de fevereiro, apenas os moradores de rua marcavam presença. Engalfinhados em meio à sujeira e aos trapos, eles ocupavam um lado da rua em que poucas pessoas passavam. Sentados nas muretas e nos degraus das escadarias que ligam a Rua da Glória à Praça Paris, eles permaneciam. Comecei a buscar os anúncios nos orelhões da rua. Nos primeiros que encontrei, apenas dois pequenos anúncios de vagas para moças em quartos de aluguel. Estavam limpos, sem nenhum sinal de cola ou papel. Parti para os telefones públicos seguintes e à medida que caminhava não encontrava nada. Mesmo quando os aparelhos se encontravam em péssimo estado de conservação, as cabines se mantinham incólumes.

Por meses passei de madrugada por ali de carro ou de ônibus. A cena de todas as noites era quase a mesma: usuários de drogas e moradores de ruas zanzando que nem zumbis e travestis corpulentas trabalhando sob a luz dos postes. Não teve uma madrugada em que esses personagens não estivessem ali. Dias quentes, chuvosos ou frios.

Resolvi avançar em direção a Rua da Lapa. A região é historicamente abrigo/morada de travestis. Antigos casarões da "Idade de Ouro", como Silva (2007) classifica o período entre as primeiras décadas do século XX até o começo da década de 1950, viraram pensões e cortiços onde as travestis vivem. Silva (2007) descreve o dia-a-dia de algumas dessas pensões e a maneira que os travestis foram ocupando a Lapa.

Talvez tenha sido a Lapa a pioneira no Brasil de um fenômeno extremamente curioso que se processou pelos fins da década de 1960, início dos anos 70, que foi a progressiva e violenta expulsão das prostitutas femininas pelos travestis que passaram a ocupar o 'bairro', dando cabo a um predomínio de sete décadas. Assim, a Lapa tornou-se muito cedo uma área de travestis, mais precisamente de prostituição de travestis (Silva, 2007, p. 45).

De acordo com Silva, o estado dessas pensões muitas vezes era marcado pela precariedade e reutilização dos espaços. Expressões como 
"fétido banheiro", "corredores escuros" e "louça suja" adjetivam as pensões cujos donos, não raro, exploram os travestis cobrando aluguéis bem acima do valor de mercado. Em visita a uma pensão, Silva, acompanhado por uma transexual - chamada Maura -, se depara com um desses ambientes. Maura precisa ir ao banheiro e pede ajuda a Silva.

Entro com ela no banheiro. Ela me confessa, uma expressão de dor: 'Já morei em tantos lugares iguais a esse... É horrível'. Fico em silêncio e olho em volta: o grande balde plástico atulhado de papéis sujos, o vaso sujo e sem tampo, a pequena janela aberta para a rua (Silva, 2007, p. 68).

Maura teria saído da Lapa. Não era um travesti e tinha realizado uma cirurgia de adequação de sexo. Passara a ser fisicamente uma mulher e proprietária de um pequeno apartamento na Avenida Prado Júnior, em Copacabana. Essa informação, não pretende ilustrar uma "evolução" (com todas as aspas possíveis) de um estágio menor para um mais elevado. A mudança de Maura indicava uma nova mancha urbana também marcada pela presença de travestis. Como isso, temos o esboço de um circuito e um trajeto percorrido pelos travestis.

Os termos "mancha", "circuito", "pedaço" e "trajeto" que utilizo nesse ensaio são apropriados de Torres (2000) que por sua vez os "apropriou" de Magnani ${ }^{3}$. São termos que se comunicam, se completam. "A mancha de lazer, por ser uma área contígua com concentração de equipamentos, é recortada por trajetos internos, percorridos por atores sociais específicos, que interligam certos estabelecimentos e não outros. Cada grupo faz desses espaços o seu pedaço." (Torres, 2000, p. 73).

Com isso a autora afirma que os trajetos não são aleatórios. Os mesmos "refletem preferências e exclusões". Temos um compartilhamento de códigos por quem percorre e habita essas manchas. "Configura-se, então, o pedaço, pois, ao mesmo tempo em que se está entre iguais e no local escolhido, há uma contraposição a outros grupos, que perfazem outros trajetos" (Torres, 2000, p. 73). E ainda, temos a possibilidade da migração de uma mancha para outra, como foi o caso de Maura.

Continuei a buscar pelos orelhões da Lapa/ Glória, mas sem sucesso. Procurei outras mar- cas que remeteriam os travestis e nada encontrei. Também não percebi nenhum travesti "a paisana" no local. Se não tivesse o costume de passar a noite pela região, dificilmente saberia que a dinâmica ali quando o sol se põe é outra. Aquela mancha estava completamente desmarcada. Ao todo contabilizei apenas oito orelhões espalhados nesse trajeto. Peguei um ônibus e fui atrás de outra mancha: Copacabana.

\section{Marcas em profusão}

Ao contrário do primeiro trajeto que foi baseado em cima da dedução de que onde há travesti, há anúncios, nessa nova mancha a certeza era quase que absoluta - o acaso seria não encontrar nada. Alguns elementos indicavam que encontraria os anúncios, o primeiro era o fato da prostituição na região ser maior. Outro elemento foi uma matéria da Revista Piauí ${ }^{4}$ que falava justamente desses anúncios.

Em "Kelvin, esse desconhecido", o repórter narrava estar em um orelhão no cruzamento das avenidas Prado Júnior e Nossa Senhora de Copacabana. Diante dos anúncios, um serviço chamou a curiosidade dele: "Kelvi" ou "Kelvin". Durante todo o texto, ele busca uma explicação para o enigma do Kelvin. O que seria esse "Kelvin"? Ele recorre ao dicionário, às enciclopédias, aos professores de português e ninguém consegue lhe responder. O repórter tenta a vizinhança dos orelhões e mais uma vez ninguém o responde. Finalmente, ele resolve ir pelo caminho que seria o mais simples: ligar para algum dos números e a resposta é ainda mais provocadora: "Só conto ao vivo", responde uma voz feminina do outro lado da linha.

Encontrar anúncios de travestis não me representava um desafio. Eles estavam nos orelhões ocupando espaço junto com os de outras prostitutas. E para quem pense que seja um artifício da profissão se passar por mulher, uma rápida olhada nos anúncios mostrava que o fato de ser travesti era algo que eles não escondiam.

Saber o que era ou não um "kelvin", nunca chegou a ser uma questão para mim. Mas, quem por ventura ficasse curioso poderia chegar perto da resposta com o anúncio de Isis. "Faço kelvi 
deixando você gozar na minha boquinha", informava junto com seus números de telefones e uma foto de mulher tendo a bunda em destaque. Isis era uma mulher e assim sendo teve seu anúncio descartado por mim.

Assim como descobrir o que era "kelvi" não representasse uma real dificuldade para o repórter, encontrar anúncios de travestis não me representava um desafio. Eles estavam nos orelhões ocupando espaço junto com os de outras prostitutas. E para quem pense que seja um artifício da profissão se passar por mulher, uma rápida olhada nos anúncios mostrava que o fato de ser travesti era algo que eles não escondiam. $\mathrm{O}$ anúncio de Isabelly era quase todo ocupado por sua foto de costas. Bunda em primeiro plano com ênfase na marquinha de praia. Cabelo escondendo parte do rosto. Fora isso só mais três informações além do nome, os números de contato, a localização Prado Júnior - e que ela era "quase mulher", nessas palavras.

Já Amandinha dava mais informações. O espaço do anúncio era dividido metade com a sua "foto verdadeira", o seu horário de atendimento - 24 horas e a outra metade com a sua descrição e serviços: "quase mulher, 20 anos, anal profundo, boquinha de veludo, ativa/passiva. Prado Júnior" e telefone de contato. Percebe-se no anúncio uma rasura feita a mão. Aliás, os anúncios chegam a ser quase artesanais. Uma colagem de textos e fotos "xerocadas" que se comparada às possibilidades gráficas entrega o amadorismo envolvido na sua confecção. Poderia qualquer pessoa coletar um desses anúncios, colar um novo número de telefone por cima e fazer novas cópias. As anunciantes mesmo fazem isso. As emendas e rasuras são bem grosseiras e de fácil percepção.

Os orelhões da Prado Júnior são muito mais numerosos que os da Rua da Lapa. Praticamente três em cada esquina. Ao todo contei 16 aparelhos. Em quase todos eles, era possível encontrar os mesmos anúncios, que se repetiam. Bia, uma quase mulher, exibia seu "bum-bum guloso" no anúncio que informava duplamente ser uma foto verdadeira. Na foto, ela aparecia de quatro com os cabelos nas costas e o desenho de um coração sobre a região do períneo. Bia, também atendia na Prado Junior e fazia "todas as suas fantasias ativa/passiva". Seu telefone de contato era o mesmo de Isabelly. Encontrei-o com o de mais uma quase mulher, Karlinha, "mulata quentíssima, cheia de fogo para dar. Ativa/passiva. Faço tudo!". A novidade: pela primeira vez (e única) apareceu uma mulata na descrição, pois, até então todas eram loiras.

O que mais destoou foi o anúncio seguinte. Darleny, "loiraça safada, 19 anos, rebolando gostoso, boca quente, show de bola. Completa..." e no final ela convida: Venha me conhecer! A foto de Darleny não informava se era verdadeira ou não, apenas que ela atendia 24 horas. Corações ornamentavam seu nome e também escondia seu rosto e ânus. O telefone de contato era o mesmo de Karlinha, Isabelly e Bia, mas ao contrário dos dois não havia a informação de que se tratava de uma mulher ou de um travesti.

Encontrei também o anúncio de Bianca e pela primeira vez no lugar do eufêmico "quase mulher", aparecia à palavra "travesti". Ela também informava usar uma "foto real" no anúncio. Descreveu-se como uma "loirinha quente" e prometia: "dou uma deliciosa massagem erótica na sua pica, sem camisinha". Bianca também atende 24 horas, mas não informava o local. Por fim, o último anúncio era de Kelly. "Travesti, loira, carinhosa com 24 motivos para te realizar". Kelly era a única cuja foto não mostrava a bunda. Apenas uma modelo loira com penteado juvenil e tênis. Outra diferença de Kelly para as demais era o fato de seu endereço ser a Avenida Nossa Senhora de Copacabana.

A medida que avança a avenida Prado Júnior em direção a orla, percebi que os anúncios começaram a diminuir a ponto de no orelhão na esquina da Avenida Atlântica com Prado Júnior não encontrar nenhum anúncio. Segui em direção a Avenida Princesa Isabel e percebi o mesmo. Quanto mais perto do mar, menos anúncios. Darleny, Bia, Bianca, Isabelly e Kelly também estavam nos 17 orelhões da Princesa Isabel - tanto do lado de Copacabana, quanto do lado do Leme. Em uma das esquinas, os anúncios chamavam a atenção de dois homens que liam e riam das mensagens. Foi a única manifestação que presenciei, até então quase sempre os orelhões estavam vazios e nos que eram utilizados, os usuários não demonstravam interesse pelas ofertas.

Em suma, nesse trajeto Prado Junior - Princesa Isabel, foram contabilizados 33 orelhões, 9 anúncios - dois de mulheres, 6 de travestis e uma não se identificou. Dos travestis, três eram loiras, um era mulata e os demais não informaram. Quase todos atendiam 24 horas, apenas dois não deram essa informação. Seis utilizavam "fotos verdadeiras". Diferente dos anúncios das mulheres que era impressos em folhas amarelas, todos 
os outros eram em folhas brancas. Nenhuma delas dizia fazer "kelvin", mas provavelmente eles o oferecem entre suas habilidades.

\section{Re-marcações na cidade}

Uma simples tarde de verão. Seis quarteirões rasgados por um trânsito constante. Um conjunto de prédios de arquitetura eclética. A mancha compreendida entre a Rua Barata Ribeiro até a Avenida Atlântica e a Avenida Princesa Isabel até a Avenida Prado Júnior não são diferentes de outras áreas de Copacabana. Porteiros em animados bate-papos. Vendedores com um olho no comércio e outro na rua. Velhinhas. Velhinhas. Velhinhas. Velhinhos. Mulheres com carinhos de bebês. Homens conversando em mesas de bar. Conversas em inglês e alemão envoltas as buzinadas e xingamentos em bom português.

\section{Nessa tradição inventada, aquela que poderia ser mais uma rua do mais famoso bairro carioca se torna uma mancha onde travestis, prostitutas e seus admiradores circulam e fazem seus trajetos de prazer e trabalho.}

Uma rua qualquer de Copacabana? Não. Copacabana não tem ruas quaisquer. Aliás, nenhum bairro tem. Sempre há uma história, uma tradição ligada a essas ruas e que as fazem únicas. Mesmo que essas histórias e tradições sejam inventadas, ou seria, principalmente se assim for.

Por tradição inventada entende-se um conjunto de práticas, normalmente reguladas por regras tácitas ou abertamente aceitas; tais práticas, de natureza ritual ou simbólica, visam inculcar certos valores e normas de comportamento através da repetição, o que implica, automaticamente, uma continuidade em relação ao passado (Hobsbawm, 1997, p. 9).

Nessa tradição inventada, aquela que poderia ser mais uma rua do mais famoso bairro carioca se torna uma mancha onde travestis, prostitutas e seus admiradores circulam e fazem seus trajetos de prazer e trabalho. Uma tradição cujo "propósito principal é a socialização, a inculcação de ideias, sistemas de valores e padrões de comportamento" (Hobsbawm, 1997, p. 17).
A presença dos anúncios acaba sendo confinada em uma "location" que Massimo Canevacci (2008) classifica como "zona", que seria a área "mais ambígua e irregular; [...]. A zona exprime o conflito social e cultural por parte dos sujeitos que, deste modo - em contraste com os planos regulares -, transformaram uma cidade em metrópole" (Canevacci, 2008, p. 33). Afinal, é difícil crer que aqueles que não estão ligados aos profissionais do sexo sejam completamente passivos e permissivos a atividade das mesmas. Isso sem contar que se esse conflito não acontece no interior da mancha, fatalmente aconteça em suas bordas. É quando a "location" zona se choca com a outra "location", chamada de "lugar-espaço". De acordo com Canevacci (2008), quando a "location" é um "lugar", ela transmite a ideia de uma identidade dada como fixa, única, compacta, certa, tradicional como as raízes do pensamento conservador. Ele segue dizendo que "o lugar determina a cidade histórica, da nascente modernidade em diante e - felizmente - colapsa com o seu declínio. O lugar é onde se inicia a cidade e termina com os muros" (Canevacci, 2008, p. 32).

Cria-se a necessidade de acordos, negociações entre as diversas Copacabanas. Códigos de convivência que segundo Beatriz Sarlo (2005), evitam que as partes entrem em guerra, mas não satisfazem a ninguém. Ao usar o exemplo da prostituição no bairro de Palermo, em Buenos Aires, a autora mostra que "o espaço público não é uma coisa definida de maneira estável, mas sim um lugar de conflito" (Sarlo, 2005, p. 71).

Os ocupantes tentam avançar (por razões legítimas ou ilegítimas, de acordo com as leis ou sem elas) e outros procuram impedi-los. $\mathrm{O}$ espaço público é um lugar de direitos e, por isso, também de obrigações. Formas legítimas de ocupação deveriam afetar o menos possível outras formas legítimas de desfrute. E digo o menos possível porque é normal que o exercício de um direito afete outros direitos. Este conflito não pode ser anulado de uma vez para sempre, mas deve ser conduzido de maneira mais ou menos satisfatória (Sarlo, 2005, p. 71).

Os relatos por sua vez "são as chaves da cidade" e através delas temos acesso ao que realmente ela (cidade) é. Mas, justamente por ser plural temos uma multiplicidade de histórias, lendas e memórias que se completam e se anulam. A cidade passa a ser palco de guerra entre relatos. Nos 
orelhões, anúncios são sobrepostos uns sobre os outros ou, ainda, retira-se um para colocar outro no lugar. Uma guerra silenciosa cujas armas são apenas papel e cola. Qual anúncio (relato) que conseguiu permanecer por mais tempo? E todos aqueles anúncios lado a lado o que querem dizer? Quem arranca os anúncios dos orelhões próximos à orla? Ao "limpar" as cabines telefônicas de bundas e ofertas sexuais, estaria reescrevendo a história daquela mancha ou determinando trajetos a serem percorridos? Quem/O que estabelece esses limites? A geografia ganha um papel secundário.

O espaço passa a ser construído, vivido e socializado baseado em táticas e estratégias. Artifícios que muitas vezes os travestis lançam mão para sobreviverem nas suas manchas. Um jogo que gira em torno da dominação e da resistência.

Embora sejam relativas às possibilidades oferecidas pelas circunstâncias, essas táticas desviacionistas não obedecem à lei do lugar. Não se definem por este. Sob esse ponto de vista, são tão localizáveis como as estratégias tecnocráticas (e escriturísticas) que visam criar lugares segundo modelos abstratos. O que distingue estas daquelas são os tipos de operações nesses espaços que as estratégias são capazes de produzir, mapear e impor, ao passo que as táticas só podem utilizá-los, manipular e alterar (Certeau, 2008, p. 92).

Há sempre necessidade de se tirar proveito dessas circunstâncias. Como já foi dito, a negociação e o conflito estão sempre presentes. É preciso saber (re)utilizar as ferramentas disponíveis e garantir assim, um dia,uma noite, um mês a mais. Os travestis precisam criar para si um espaço de jogo "para maneiras de utilizar a ordem imposta do lugar e da língua. Sem sair do lugar onde tem que viver e que lhe impõe uma lei, ele aí instaura pluralidade e criatividade. Por uma arte de intermediação ele tira daí efeitos imprevistos" (Certeau, 2008, p. 93).

Dentro das manchas vemos os travestis traçando "trajetórias indeterminadas", cujo sentido nem sempre é coerente com o espaço construído, escrito e pré-fabricado onde se movimentam. Eles subvertem a ordem que lhe são "impostas", o toque de recolher é estendido. Se a noite, eles já são os donos do pedaço, de dia com seus anúncios, eles mordem mais uma lasca do lugar. Através das táticas eles resistem a ordem estabelecida e com suas táticas eles se utilizam das brechas que encontram. Astutos, os travestis garantem seu movimento e seu lugar. E se alguém retirar os anúncios é provável que, num curto tempo, outro apareça no lugar.

\section{Re-marcações no corpo}

Uma mulher com um corpo de homem ou um homem com corpo de mulher? Categorizar os travestis não é das tarefas mais simples. Não se trata de um homem com "alma feminina" ou de uma mulher com pênis. Seria um terceiro sexo? Mas, que sexo seria esse? Talvez, um caminho para se discutir os travestis comece justamente em abrir mão do binarismo homem-masculino/ mulher-feminino. Também é necessário, fazer um distinção clara entre sexo e gênero. Todavia, o caminho é extenso e acidentado.

Judith Butler (2008) chama atenção para o fato de que a simples cisão entre sexo e gênero levanta um conjunto de problemas. "Podemos referir-nos a um 'dado' sexo ou um 'dado' gênero sem primeiro investigar como são dados o sexo e/ou gênero e por que meios? E o que é, afinal? o 'sexo'?", exemplifica a autora (Butler, 2008). Butler (2008) também alerta para definição de que o gênero é nada mais que uma interpretação cultural do sexo. Para ela, o gênero não dever compreendido como uma simples "inscrição cultural de um significado num sexo previamente dado" e que é preciso designar também o "aparato mesmo de produção mediante o qual os próprios sexos são estabelecidos" (Butler, 2008)

Resulta daí que o gênero não está para a cultura como o sexo para a natureza; ele também é um meio discursivo/cultural pelo qual "a natureza sexuada" ou "sexo natural" é produzido e estabelecido como "pré-discursivo", anterior à cultura, uma superfície politicamente neutra sobre a qual age a cultura. "[...]. Na conjuntura atual, já está claro que colocar a dualidade do sexo num domínio pré-discursivo é uma das maneiras pelas quais a estabilidade interna e a estrutura binária do sexo são eficazmente asseguradas. Essa produção do sexo como pré-discursivo deve ser compreendida como efeito do aparato de construção cultural que designamos por gênero" (Butler, 2008, p. 25-26).

Butler desconstrói a ideia de que a cultura era determinante na constituição do gênero. O determinismo cultural tornaria o gênero em algo tão 
fixo da mesma forma que a biologia fixa o sexo. A construção do gênero seria para uma controvérsia envolvendo dois pólos, o livre-arbítrio e o determinismo.

Em consequência, seria razoável suspeitar que algumas restrições linguísticas comuns ao pensamento tanto formam como limitam os termos do debate. Nos limites desses termos, "o corpo" aparece como um meio passivo sobre o qual se inscrevem significados culturais, ou então como o instrumento pelo qual uma vontade de apropriação ou interpretação determina o significado cultural por si mesma. Em ambos os casos, o corpo é representado como um mero instrumento ou meio com o qual um conjunto de significados culturais é apenas externamente relacionado (Butler, 2008, p. 27).

Porém, o corpo é por si só uma construção e inúmeras possibilidades de "corpos" cheios de marcas que constituem o sujeito. $\mathrm{O}$ gênero e o sexo tem sua fluidez ou fixação em função de um discurso que busca estabelecer certos limites. É justamente a superação desses limites que é defendida por Butler (2008). O rompimento com o determinismo cultural ou biológico também faz parte dessa superação. Afinal, "como fenômeno inconstante e contextual, o gênero não denota um ser substantivo, mas um ponto relativo de convergência entre conjuntos específicos de relações, cultural e historicamente convergentes" (Butler, 2008). O travesti então estaria "livre" de uma classificação rígida na qual deveria optar em ser ou homem ou mulher, seria justamente resultado de vários fatores não dominantes entre si.

0 corpo é por si só uma construção e inúmeras possibilidades de "corpos" cheios de marcas que constituem o sujeito. 0 gênero e 0 sexo tem sua fluidez ou fixação em função de um discurso que busca estabelecer certos limites.

Segundo Butler (2008), apesar do gênero não ser substantivo, este também não é um conjunto de "atributos flutuantes". É fruto de uma produção disciplinar que leva o efeito de uma "falsa estabilização do gênero", no interesse da construção e padrões heterossexuais da sexualidade no domínio reprodutor.
A construção da coerência oculta as descontinuidades do gênero, que grassam nos contextos heterossexuais, bissexuais, gays e lésbicos, nos quais o gênero não decorre necessariamente do sexo, e o desejo, ou a sexualidade em geral, não parece decorrer do gênero - nos quais, a rigor, nenhuma dessas dimensões de corporeidade significante expressa ou reflete outra. Quando a desorganização e desagregação do campo dos corpos rompe a ficção reguladora da coerência heterossexual, parece que o modelo expressivo perde sua força descritiva. O ideal regulador é então denunciado como norma e ficção que se disfarça de lei do desenvolvimento a regular o campo sexual que se propõe descrever (Butler, 2008, p. 194).

A autora prossegue afirmando que, apesar da ruptura, há um desejo, uma idealização pela coerência resultantes da significação corporal.

Em outras palavras, atos, gestos e desejo produzem o efeito de um núcleo ou substância interna, mas o produzem na superfície do corpo, por meio do jogo de ausências significantes, que sugerem, mas nunca relevam, o princípio organizador da identidade como causa (Butler, 2008, p. 194).

Butler (2008) classifica esses atos, gestos e atuações como "performativos", no sentido que a identidade nesse caso expressa "fabricações manufaturadas e sustentada por signos corpóreos" (Butler, 2008). Essa performance seria resultado de uma gama de interações entre os discursos externo e interno. Em seguida, a autora afirma que sendo a "verdade interna" uma fabricação, e com isso o gênero tido como verdadeiro é uma espécie de fantasia inscrita na superfície dos corpos, os gêneros não poderiam ser classificados nem como falso, nem como verdadeiros. Os gêneros seriam somente "produzidos como efeitos da verdade de um discurso sobre a identidade primária e estável". (Butler, 2008)

Finalmente, Butler (2008) usa a figura do travesti com exemplo de total subversão da distinção entre o interno e o externo (espaços psíquicos). O travesti ainda ignoraria a ideia de uma verdadeira identidade de gênero. Não é a toa que encontramos nos anúncios o uso dos termos "quase mulher".

Em sua expressão mais complexa, (o travesti) é uma dupla inversão que diz que "a 
aparência é uma ilusão". O travesti diz (curiosa personificação de Newton): "minha aparência 'externa' é feminina, mas minha essência 'interna' (o corpo) é masculina". Ao mesmo tempo, simboliza a inversão oposta: "minha aparência 'externa' (meu corpo, meu gênero) é masculina, mas minha essência 'interna' (meu eu) é feminina" (Newton apud Butler, 2008, p. 195-196).

Prosseguindo, Butler (2008) chama atenção para o fato das frases de Newton se anularem e com isso, eliminando a possibilidade de um discurso do verdadeiro ou do falso. Também destaca o fato da travestilidade e as performances de drag queens a noção de uma identidade original de gênero é tratada de forma parodiada para a irritação de algumas feministas que entendem tal ato como degradante para a mulher. Porém, para a autora a relação entre a "imitação" e o "original" seria bem mais completa.

A performance do drag brinca com distinção entre a anatomia do performista e o gênero que está sendo performado. Mas estamos, na verdade, na presença de três dimensões contingentes da corporeidade significante: sexo anatômico, identidade de gênero e performance de gênero. Se a anatomia do performista já é distinta de seu gênero, e os dois se distinguem do gênero da performance, então a performance sugere uma dissonância não só entre sexo e performance, mas entre sexo e gênero, e entre gênero e performance. Por mais que crie uma imagem unificada da "mulher" (ao que seus críticos se opõem frequentemente), o travesti também revela a distinção de aspectos da experiência do gênero que são falsamente naturalizados como uma unidade através da ficção reguladora da coerência heterossexual (Butler, 2008, p. 196).

É como se a imitação revelasse a "estrutura imitativa do próprio gênero" (Butler, 2008). Sendo assim, uma mulher seria tão imitadora quanto um travesti. Na verdade, a paródia não seria de um original, e sim da ideia de um original. A imitação reforçaria a noção de que o gênero original imitada não existe. “Esse deslocamento perpétuo constitui uma fluidez de identidades que sugere uma abertura à re-significação e à recontextualização; a proliferação parodística priva a cultura hegemônica e seus críticos da reivindicação de identidades de gênero naturalizadas ou essencializadas" (Butler, 2008).
A negação de um gênero original, mostra de acordo com Berenice Bento (2006) que não há corpos livres, anteriores aos investimentos discursivos. A materialidade do corpo deve ser estudada como efeito de um poder e o sexo não é aquilo que alguém tem ou uma descrição estática.

O sexo é uma das normas pelas quais o "alguém" simplesmente se torna viável, que qualifica um corpo para a vida no interior do domínio da inteligibilidade. Há uma amarração, uma costura, ditada pelas normas, no sentido de que o corpo reflete o sexo, e o gênero só pode ser entendido, só adquire vida, quando referido a essa relação. As performatividades de gênero que se articulam fora dessa amarração são postas às margens, pois são analisadas como identidades "transtornadas" pelo saber médico (Bento, 2006, p. 3).

Bento reforça a ideia de que o sistema binário de gêneros produz e reproduz a ideia de que o sexo é refletido pelo gênero. A partir dessa ideia todas as demais relações estariam naturalmente determinadas. Para a autora (Bento, 2006) esse binarismo é um equívoco, e para reforça o seu pensamento ela recorre ao conceito "performatividade quer" de Butler (2008) que possibilitam o aparecimento de práticas que quebram a reprodução de normas de gênero. "a performatividade não é um "ato" único, singular: são as reiterações das normas ou conjunto de normas. $\mathrm{O}$ fato de adquirir o status de um ato no presente gera o ocultamento das convenções drag queen das quais ela deriva" (Butler, 2008).

A fuga do binarismo também representa o fim da subordinação do corpo para com o saber médico. De acordo com Bento (2006), travestis, gays, e afins, tem sido ao longo do tempo objetos de estudo e intervenção de um saber que visa a normalização. Segundo a autora (Bento, 2006), no momento que se rompe com a "determinação natural das condutas" , também se põe em xeque esse ponto de vista que analisa os deslocamentos enquanto "sintomas de identidade pervertidas, transtornadas e psicóticas".

A radicalização da desnaturalização das identidades, iniciada pelos estudos e políticas feministas, apontará que a identidade de gênero, as sexualidades, as subjetividades só apresentam uma correspondência com o corpo quando é a heteronormatividade que orienta o olhar (Bento, 2006, p. 22). 
Para finalizar, Pelúcio (2008) nos trás algumas considerações sobre a identidade dos travestis. A primeira consideração é que a identidade não se pode ser entendida com algo cristalizado, estaque. Uma vez tida essa compreensão corre-se o risco da identidade não representar nada além de uma imagem ultrapassada de um indivíduo que "não existe mais". No caso dos travestis, essa não cristalização é ainda mais necessária. Categorizar a experiência identitária de um travesti é uma tarefa complicada.

Negociar símbolos, práticas e estéticas socialmente vinculados ao feminino em corpos pretensamente masculinos, um comprometimento com esta feminilidade sem, no entanto, existir a pretensão de outorgar-se mulher, talvez seja um bom ponto inicial para tecer nossas considerações. Resultando em diferentes configurações, estas negociações não são puramente idiossincráticas, são organizadas pelas normas sociais e de gênero que permeiam e regulam os contextos sociais onde as travestis se inserem mas também por uma série de práticas, gostos e tecnologias de gênero legitimamente relacionadas ao projeto travesti (Pelúcio, 2008, p. 02).

O travesti rompendo com as configurações pênis-masculinidade-homem-penetração (em uma mulher) e vagina-feminilidade-mulher-ser penetrada (por um homem) acaba tendo a materialização do gênero questionado. Uma vez que o gênero é construído, negociado e jamais determinado, os travestis tem sua identidade de gênero legitimada como qualquer outra configuração incluindo ainda as diferenças e transformações possíveis.

"Hormonizadas" ou não, com seus longos e bem tratados cabelos naturais ou apliques sintéticos, toda "quebrada na plástica" ou sem as doses generosas de silicone líquido em seus corpos as travestis não são facilmente encapsuladas pelos discursos que almejam representá-las. Não apenas seus corpos são fluídos, produtos vivos de um projeto que busca a perfeição de um feminino glamoroso, como são heterogêneos indo das atuais "ninfetinhas" que povoam as áreas de prostituição de rua atualmente existentes em praticamente todos os grandes centros urbanos brasileiros, passando pelas "divas", "tops" e "europeias", até chegar na "travecão" com suas curvas exageradas ligadas ao insucesso e ao ultrapassado (Pelúcio, 2008, p. 03).
De acordo com Pelúcio (2008), o "Projeto travesti" é organizado por numerosos e complexos elementos. Primordialmente, tem se a ideia de que o travesti almeje construir em seu corpo uma feminilidade que não lhe é reconhecida socialmente como feminino. Levando em consideração a presença da genitália masculina, temos um nó que revela a "verdade" sobre aquele corpo. Porém, a autora (Pelúcio, 2008) afirma que ser travesti é muito mais que marcar o corpo as mudanças rumo a essa "verdade". O corpo é apenas o veículo pelo qual será construída "toda uma subjetividade também marcada pelas negociações entre o feminino e o masculino". A genitália passa a segundo plano na construção desse feminino. Gestos, olhares, aumento dos seios e das coxas são alguns dos artifícios na construção do travesti. Não que sejam esses os elementos que fazem ou desfazem uma orientação de gênero, mas sim por que são eles os observados e vigiados durante a negociação.

Atrelar esta materialização do feminino em corpos dotados de pênis à ingestão de hormônios, as modificações corporais com silicone líquido e a prostituição são apenas ideias primárias que dizem muito (ou muito pouco) sobre a experiência travesti. Se a travestilidade não é uma experiência que pertence ao sujeito, mas vivenciar tal experiência é o que a conforma enquanto travesti tais negociações e apropriações serão tão contingentes e específicas dentro de contextos concretos quanto à própria travestilidade (Pelúcio, 2008, p. 04).

Percebe-se assim, que a delimitação total da travestilidade é uma tarefa inconclusiva. $\mathrm{O}$ caminho encontrado por Pelúcio (2008) é recorrer a uma série de questionamentos sobre os travestis. "Tendo tais questões em mente podemos compreender até que ponto os discursos que descrevem as travestis são significativos para elas, ou mesmo qual o poder descritivo que o termo travesti ainda mantém" (Pelúcio, 2008), conclui a autora. Pelúcio (2008) faz um resgate sobre tentativas de uso de novos termos que designariam os travestis, dentre eles, "trangêneros" que após muito debate entrou em desuso antes mesmo de ser usado; e "transex" que foi a forma encontrada pelos travestis de se autoclassificar na tentativa de fugir do estigma da marginalidade atrelado ao termo "travesti". Estariam estão sendo criadas novas identidades de gêneros ou seria o fim da performance conhecida pelos travestis? 


\section{Prolongo [...]}

O mar de Copacabana vai ficando ao fundo. Talvez se não houvesse nenhum daqueles automóveis seria possível ouvir o barulho das ondas. Não, não seria. Ainda haveria o som das vozes das pessoas, o barulho das reformas dos prédios - em Copacabana, construção de edifícios passou a ser uma raridade -, tem o vento balançando as árvores ou as televisões. A paisagem do bairro vai além de areia e ondas. Cruzo com um travesti dentro de um microvestido que parecia ter sido costurado ao corpo de tão justo que era. Morena, alta, cabelos pretos encaracolados não chamava mais atenção do que um corpo belo pode chamar. Passou rápida e sem olhar para os lados, muito menos para trás.

Na porta de um Sex-Shop homens conversam animadamente com policiais a trabalho. Todos em frente a vitrine com suas camisolas eróticas e outros artifícios. O movimento nos bares não era frenético. Viro a esquina, mais carros e ônibus. Atravesso a avenida e resolvo voltar a pé para casa. Entro no Túnel do Leme - até então não sabia que ele tinha esse nome. As luzes queimadas deixam tudo ainda mais escuro. O ruído é horrível. Todos que passam ali parecem ter pressa. Por mais que eu ande, tenho a sensação de estar numa esteira na direção contrária. Copacabana vai ficando para trás, mas bem devagar.

$\mathrm{Na}$ minha mochila alguns exemplares dos anúncios. Tomei o cuidado de não pegar "cópias únicas", afinal não queria tirar de circulação nenhuma daquelas quase-mulheres. Por sorte, nenhum deles eram econômicos e sempre colavam mais de um anúncio por orelhão. Percebi que a cola servia apenas para prender o papel na superfície do orelhão de forma que não dificultasse a retirada. Um potencial cliente necessariamente não vai atrás dos orelhões em busca de programa, mas pode acidentalmente encontrar um anúncio que o atraia. Afinal, não é possível manter-se blasé diante do mergulho compulsório de ofertas cada vez que se usa o telefone público. $\mathrm{O}$ interesse pode surgir entre um número ocupado ou entre ligações. E nesse caso, retirar o anúncio é muito mais rápido que anotar num papel ou na agenda do celular. Pode-se ainda usar a desculpa de "estar limpando o telefone daquelas nojeiras", para disfarçar os olhares curiosos.

Os anúncios demarcam sem dúvida um território em meio a tantos outros que existem em
Copacabana. Cada papel colado nos orelhões é uma peça para transformar aquela região em um "pedaço" deles. É uma estratégia de dominação do espaço. É como se eles realmente fossem seres 24 horas como tanto anunciam. Na ausência dos corpos físicos, os anúncios marcam ponto até o cair da noite.

\section{REFERÊNCIAS}

BENTO, Berenice. A reinvenção do corpo : sexualidade e gênero na experiência transexual. Rio de Janeiro: Garamond, 2006.

“Corpos e Próteses: dos Limites Discursivos do Dimorfismo". Artigo apresentado no $7^{\circ}$ Seminário Internacional Fazendo Gênero. Florianópolis: 2006.

BUTLER, Judith. Problemas de gênero: Feminismo e subversão da identidade. Rio de Janeiro: Civilização Brasileiro, 2008.

CANCLINI, Néstor García. Culturas Híbridas - Estratégias para entrar e sair da modernidade. São Paulo: EdUsp, 1998.

CANEVACCI, Massimo. Fetichismos Visuais - Corpos Erópticos e a Metrópole Comunicacional. São Paulo: Ateliê Cultural, 2008.

CERTEAU, Michel de. A Invenção do Cotidiano - 1. Artes do fazer. Petrópolis: Vozes, 2008.

A invenção do Cotidiano - 2. Morar, cozinhar. Petrópolis: Vozes: 2000.

HOBSBAWN, Eric. Introdução: A Invenção das Tradições. In: HOBSBAWN, Eric; RANGER, Terence (Orgs.). A Invenção das Tradições. Rio de Janeiro: Paz e Terra, 1997.

PELÚCIO, Larissa. Experiências plurais em categorias singulares: Problematizando a materialização das travestilidades. Artigo apresentado no $8^{\circ}$ Seminário Internacional Fazendo Gênero. Florianópolis:2008.

SARLO, Beatriz. Tempo Presente - Notas sobre a mudança de uma cultura. Rio de Janeiro: José Olympio, 2005.

SILVA, Hélio R.S. Travestis: entre o espelho e a rua. Rio de Janeiro: Rocco, 2007.

TORRES, Lilian de Lucca. Programa de Paulista. In: MAGNANI, José Guilherme; TORRES, Lilian de Lucca (Orgs.). Na Metrópole: Textos de Antropologia Urbana. São Paulo: Edusp, 2000.

\section{NOTAS}

1 O artigo foi elaborado na primeira pessoa do singular para ressaltar o método etnográfico.

2 Rio 40 Graus - Composição de Fernanda Abreu, Fausto Fawcett e Laufer.

3 MAGNANI, José Guilherme C. Da periferia ao Centro: pedaços e trajetos. Revista de Antropologia, São Paulo, p. 35, 1992.

4 KAZ, Roberto. Kelvi, esse desconhecido - Uma esquina X-rated. Revista Piauí, Rio de Janeiro, n. 29, p. 5, 2009. 